\title{
What Stakeholder Needs Tell Us about Enabling Adaptive Capacity: The Intersection of Context and Information Provision across Regions in the United States
}

\author{
LISA DILLING \\ Center for Science and Technology Policy Research, and Western Water Assessment, Cooperative Institute for \\ Research in Environmental Sciences, and Environmental Studies Program, University of \\ Colorado Boulder, Boulder, Colorado \\ Kirsten Lackstrom, Benjamin Haywood, and Kirstin Dow \\ Department of Geography, and Carolinas Integrated Sciences and Assessments, University of South \\ Carolina, Columbia, South Carolina \\ MARIA CARMEN LEMOS \\ Great Lakes Integrated Sciences and Assessment, School of Natural Resources and Environment, \\ University of Michigan, Ann Arbor, Michigan

\section{JOHN BERGGREN} \\ Center for Science and Technology Policy Research, and Western Water Assessment, Cooperative Institute for \\ Research in Environmental Sciences, and Environmental Studies Program, University of \\ Colorado Boulder, Boulder, Colorado

\section{SCOTT KALAFATIS} \\ Great Lakes Integrated Sciences and Assessment, School of Natural Resources and Environment, \\ University of Michigan, Ann Arbor, Michigan
}

(Manuscript received 6 January 2014, in final form 21 August 2014)

\begin{abstract}
In recent years increasing attention has been focused on understanding the different resources that can support decision makers at all levels in responding to climate variability and change. This article focuses on the role that access to information and other potential constraints may play in the context of water decision making across three U.S. regions (the Intermountain West, the Great Lakes, and the Carolinas). The authors report on the degree to which climate-related needs or constraints pertinent to water resources are regionally specific. They also find that stakeholder-identified constraints or needs extended beyond the need for data/information to enabling factors such as governance arrangements and how to improve collaboration and communication. As climate information networks expand and emphasis is placed on encouraging adaptation more broadly, these constraints have implications not only for how information dissemination efforts are organized but for how those efforts need to be informed by the larger regional context in a resource-limited and fragmented landscape.
\end{abstract}

Corresponding author address: Lisa Dilling, Environmental Studies and CIRES/CSTPR, University of Colorado Boulder, 1333 Grandview Ave., Boulder, CO 80304.

E-mail: ldilling@colorado.edu

\section{Introduction and background}

Communities, governments, businesses, and individuals are increasingly recognizing that climate affects resource management and livelihood options and that planning for 
and adjusting to climate variability and change are needed. However, the pace of adaptation for climate change is still relatively modest and awareness of available options is low (Bierbaum et al. 2013). To support the ability of decision makers at all levels to respond to climate, much attention has been focused in recent years on better understanding the resources that are needed for adaptation and what the challenges to effective adaptation might be (Moser and Ekstrom 2010; Moss et al. 2013).

Designing and implementing effective adaptation strategies depends on adaptive capacity, defined by the Intergovernmental Panel on Climate Change (IPCC) as "the ability or potential of a system to respond successfully to climate variability and change, and includes adjustments in both behaviour and in resources and technologies" (Adger et al. 2007, p. 727). Many scholars have suggested that access to information is critical among theorized determinants of adaptive capacity (Eakin et al. 2011; Smit and Wandel 2006; Yohe and Tol 2002). The rationale is that stakeholders armed with salient, credible, and legitimate information can make better-informed decisions about how to prepare and respond to climate impacts (Cash et al. 2006; Jacobs et al. 2010). And while this assumption makes sense in principle, empirical research shows that the application of climate information can be quite challenging, especially in the climate adaptation decision context (Kirchhoff et al. 2013; Moss et al. 2013; Weichselgartner and Kasperson 2010). Even climate information that is intended specifically to support decision making is often underutilized despite increasing availability (Weichselgartner and Kasperson 2010).

One frequently mentioned challenge to the effective deployment of climate information is our lack of understanding of how different decision contexts in which adaptation choices are made affect and are affected by knowledge production and use (Dilling and Lemos 2011; Feldman and Ingram 2009; Hegger et al. 2012; Lowrey et al. 2009; Simpson et al. 2013, manuscript submitted to Climate in Context). In its broadest conception, the decision context encompasses the human, cultural, institutional/organizational, political, and socioeconomic factors that influence climate decision makers' willingness and ability to use climate information, particularly for adaptation. It can also include the natural and built environments that shape the impact of climate change and variability. Research and guidance on decision-making processes identifies clarifying the decision context as the first step to designing structured decision-making support systems (Gregory et al. 2012). While the adaptation literature gives significant attention to the constraints and challenges to climate information use (Dilling and Lemos 2011; Klein et al. 2014), there is relatively less effort on understanding decision contexts and how a better understanding of context could inform the production of relevant information.

In this paper we report on a comparative research project, carried out within the scope of the National Oceanic and Atmospheric Administration (NOAA) Regional Integrated Sciences and Assessments (RISA) program, ${ }^{1}$ specifically designed as a first step to describe the decision context of climate policy in three U.S. regions (the Carolinas, the Great Lakes, and the Intermountain West). Our initial goals were twofold. First, we sought to explore how climate policy-oriented documents could be used to develop an understanding of how decision makers and stakeholders define not only the scope of the problem and policy priorities for climate action in each region but also their knowledge and information needs. In doing so, we also considered insights that could inform climate information producers about the decision context for climate science. Second, we sought to understand to what degree stakeholder needs are common across regions and whether findings from one region might be transferable to another. In designing our methodology we considered two other factors: first, we sought to avoid "stakeholder fatigue" (Jacobs et al. 2005; Kasperson 2006) by assuming the documents to be an expression of stakeholders' views given the documents' origin, and second, we viewed these efforts as a point of departure rather than a destination as we continue to collect data to further describe decision contexts of interest [for an example of this work, see Dow et al. (2013) and Kalafatis et al. (2014, manuscript submitted to Global Environ. Change)]. By better understanding the role of regional variation in decision contexts and information needs, we hope that results from this study can inform questions about the degree to which needed U.S. adaptation information can be developed for common use and in what circumstances information must be regionally specific to be useful.

In the following section, we briefly review the literature focusing on information usability and decision contexts. Then, we describe our methods and research approaches. Next, we discuss how climate affects water resource decision making in our respective regions, expressed here as concerns about climate, noting commonalities and differences. We then present the results of our document review of stakeholder needs, analyzing findings within emergent categories of data and information, governance, and communication. We also consider the implications of these findings for the future evolution of decision-support activities.

\footnotetext{
${ }^{1}$ Funded by NOAA to produce and disseminate stakeholder-driven climate information.
} 


\section{Information use and decision context}

Through the years, scholars and managers of science have suggested and designed different strategies to enhance the use of science in decision making, including creating and developing boundary organizations and decision-support networks, engaging in the coproduction of science and policy, and developing specific tools and methods to improve information use (Cash 2001; Cash et al. 2003; Feldman and Ingram 2009; Gregory et al. 2012, McNie 2007). Research has also sought to improve understanding of the diverse factors that influence decision making (e.g., Jacobs et al. 2005; Ray et al. 2007; Rayner et al. 2005). However, despite these efforts, a "climate information usability gap" (Lemos et al. 2012) continues to challenge our ability to build capacity for climaterelated decision making.

Several potential reasons for this usability gap exist, including an unsupportive context for incorporating climate information and a disconnected research process that fails to account for relevance, fit, timeliness, and accessibility of information it produces (Dilling and Lemos 2011; Sarewitz and Pielke 2007). For example, there is robust empirical evidence that climate information by itself is insufficient to support adaptive action in the absence of conducive institutional factors, financial support, or other forms of capacity at the municipal or other levels (Glaas et al. 2010; Klein et al. 2014; Naess et al. 2005; Tribbia and Moser 2008).

The usability gap may also be influenced by organizational and institutional practices in producing knowledge and seeking information (Roncoli et al. 2012). For example, most organizations tend to focus on particular goals and objectives, or at least attempt to do so, as an organization's credibility can be threatened if it departs too far from a mission for which it is trusted into a realm where it is not trusted (Lach et al. 2003; Pielke 2007). Similarly, stakeholders tend to trust specific organizations for their information, whether it be a government agency, a favorite trade magazine, a supply vendor, or a neighbor (Archie et al. 2014; Dilling and Failey 2013; Lackstrom et al. 2014). In some cases, knowledge networks form among those who are likely to share interests and views, although the narrower scope of interactions can also result in blind spots to activities or work occurring outside a specific network (Bidwell et al. 2013).

Decision-support processes are more successful if they begin with users' needs in mind (National Research Council 2009), which in turn is a compelling reason to engage stakeholders in research and design of decisionsupport tools. However, the process of convening researchers and stakeholders to iteratively scope and define decision needs and how they can be met by currently available knowledge requires significant time and investment from both parties (Jacobs et al. 2010; Lemos et al. 2014). There may also be outright barriers and high transaction costs to the collaborative production of usable information such as lack of trust, different needs and objectives, different incentives, and different standards of credibility and legitimacy between potential partners (Lemos et al. 2014; Weichselgartner and Kasperson 2010). As the number of decision makers and sectors that need climate information at increasingly finer scales grows, so does the challenge of building and maintaining highly interactive relationships between scientists and stakeholders (Lemos et al. 2012). On the one hand, the number of scientists potentially available and willing to engage stakeholders may pose a limitation; on the other hand, stakeholders themselves may become frustrated or fatigued by repeated requests to participate in such interactions (Jacobs et al. 2005; Kasperson 2006).

Finally, the information provision context has expanded and grown more complex in recent years. Just in the past few years, many different efforts seeking to provide climate information and adaptation support for decision making have emerged (Bierbaum et al. 2013). In this environment of burgeoning effort and rising awareness coupled with increasingly constrained financial and personnel resources, the challenge becomes how to meet the climate-related needs of decision makers effectively over the short and long term.

\section{Methods}

Three research teams from different regions of the United States collaborated on this project. Each team is a member of the NOAA RISA program. Individual RISAs are organized at a scale of several U.S. states and work to 1) characterize the state of knowledge of climate variations and changes at appropriate scales of interest, 2) identify knowledge gaps and linkages in selected climateenvironment-society interactions, and 3) provide an informed basis for responding to climate-related risks and establishing priorities in basic research investments to meet these needs (Pulwarty et al. 2009). In the context of RISAs, interdisciplinary teams of scientists engage with regional-, state-, and local-level decision makers to pursue these goals. Study teams represent the Carolinas Integrated Sciences and Assessments (CISA) working in North and South Carolina, the Great Lakes Integrated Sciences and Assessment Project (GLISA) covering the U.S. states and Canadian provinces within the Great Lakes watershed, and the Western Water Assessment (WWA) focusing on the U.S. states of Colorado, Wyoming, and Utah (see Table 1). 
TABLE 1. Number of documents analyzed per RISA team.

\begin{tabular}{|c|c|c|}
\hline \multicolumn{3}{|c|}{ RISA teams } \\
\hline CISA & GLISA & WWA \\
\hline \multicolumn{3}{|c|}{ Geographical boundaries covered by RISA teams } \\
\hline $\begin{array}{l}\text { North } \\
\text { Carolina, } \\
\text { South } \\
\text { Carolina }\end{array}$ & $\begin{array}{l}\text { Great Lakes basin, } \\
\text { including all or portions } \\
\text { of Illinois, Indiana, } \\
\text { Michigan, Minnesota, } \\
\text { New York, Ohio, On- } \\
\text { tario, Pennsylvania, } \\
\text { Wisconsin }\end{array}$ & $\begin{array}{l}\text { Colorado, } \\
\text { Utah, } \\
\text { Wyoming }\end{array}$ \\
\hline
\end{tabular}

\begin{tabular}{|c|c|c|c|}
\hline \multicolumn{4}{|c|}{ No. of documents, by primary sector* } \\
\hline Agriculture & $\mathrm{n} / \mathrm{a}$ & 25 & 1 \\
\hline Forestry & 2 & 11 & $\mathrm{n} / \mathrm{a}$ \\
\hline $\begin{array}{l}\text { Municipal-regional } \\
\text { planning and management }\end{array}$ & 15 & 17 & $\mathrm{n} / \mathrm{a}$ \\
\hline $\begin{array}{l}\text { Natural resources and } \\
\text { wildlife }\end{array}$ & 5 & 18 & 10 \\
\hline Recreation and tourism & 1 & 20 & 3 \\
\hline Tribes & $\mathrm{n} / \mathrm{a}$ & 4 & 2 \\
\hline Water management & 6 & 33 & 26 \\
\hline Multiple & 17 & 26 & 13 \\
\hline \multicolumn{4}{|c|}{ No. of documents, by year } \\
\hline 1997 & & 2 & \\
\hline 1998 & & 0 & 3 \\
\hline 1999 & & 0 & 0 \\
\hline 2000 & & 1 & 1 \\
\hline 2001 & & 2 & 0 \\
\hline 2002 & & 1 & 1 \\
\hline 2003 & & 3 & 2 \\
\hline 2004 & & 1 & 1 \\
\hline 2005 & 2 & 3 & 0 \\
\hline 2006 & 0 & 2 & 6 \\
\hline 2007 & 1 & 6 & 7 \\
\hline 2008 & 18 & 9 & 10 \\
\hline 2009 & 8 & 9 & 11 \\
\hline 2010 & 17 & 2 & 9 \\
\hline 2011 & & 1 & 4 \\
\hline Total & 46 & 42 & 55 \\
\hline
\end{tabular}

* GLISA used nonexclusive designations.

This project was conducted from September 2010 to July 2011. Seeking to understand the decision context that shapes climate information needs and recognizing that a substantial number of reports on climate variability and change and societal response have already been developed in the study areas, the research teams used existing documents to obtain information about expressed stakeholder concerns related to climate variability and change. For the individual teams, the first step was to build a comprehensive database of stakeholders with an interest and investment in climate, including key characteristics and needs specific to their sectors and regions. We expected this information to provide insights not only about regional priorities and challenges but also about existing science-policy-practice networks between researchers and local stakeholders.
Each team conducted an open-ended, web-based search for policy-oriented documents that focused on some aspect of climate variability and change or a related mitigation or adaptation topic. Discussions with key informants augmented the web search to ensure that critical documents were not overlooked. Searches centered on finding documents produced by or in conjunction with stakeholders or that provided information about sectoral or stakeholder perspectives about climate concerns, activities, and needs. The initial step was for each team to catalog all documents in Microsoft Access and Excel with relevant descriptors (e.g., year of publication, sponsoring organization or author(s), and topic of focus). The final databases consisted of technical reports, workshop and conference summaries, impact assessments, and local and regional climate action plans.

The teams communicated throughout the document search process to compare progress and results. The types of documents available in each of the regions varied. While GLISA and WWA focused on obtaining documents specific to climate change and variability, CISA found very few documents that addressed climate change explicitly and searched more broadly for materials that demonstrated how different sectors in the Carolinas were discussing climate-related risks. Table 1 shows the breakdown of documents by research team according to year and a distribution of documents by primary sector of interest.

In the second step of the project, the teams developed a common framework to analyze documents and to use that framework to compare themes and patterns that emerged within and across regions. To this end, the full research team developed a shared coding protocol to analyze documents using the software NVivo. The protocol outlined critical variables of interest and procedures for classifying documents into broad predefined categories. These variables included stakeholders' concerns about climate; the types of existing or planned activities (adaptation or mitigation) occurring in each sector; constraints or barriers related to planning or implementation of activities; recommendations or possible solutions to address adaptation limits and barriers; and the types of networks, key organizations, and individuals involved (e.g., climate information sources, partnerships, and funding sources). Researchers from the three teams participated in regular conference calls and webinars to ensure that each team utilized the same coding categories, although each team coded their individual documents separately. While this paper focuses on the comparative needs and adaptive capacity related to water resources in the three regions, the individual RISA teams provide additional analysis regarding region-specific capacities, networks, and needs in other 
reports (see Dilling and Berggren 2014; Dow et al. 2013; Frank et al. 2012; Haywood et al. 2014; Lackstrom et al. 2014).

Our study is limited in that it focused only on documents, which by nature only reflect the point of view of the documents' authors. In addition, our sampling technique may have missed some documents that were not available online (Yin 2003). However, each document does represent a snapshot in time of the discussion or conclusions by a group of decision makers and can point to larger patterns in thinking and action regarding climate change impact.

\section{Results}

A potential increase in precipitation variability was a common concern across all of the regions, but expressions of information needs illuminated distinct regional decision contexts. Here we present analysis of results regarding these concerns and challenges. First, we briefly discuss the ways in which regional socioecological pressures interact with increased precipitation variability to create unique water-related priority concerns and challenges. Second, we summarize and discuss how stakeholders described the resources and capacities needed to address climate variability and change in the water sector.

\section{a. Regional concerns about climate and water resources}

While all regions have experience with climate variability and have developed coping strategies to manage extreme events such as drought, Fig. 1 demonstrates how regional water-related concerns and priorities emerge through the interaction of expected precipitation changes with regional socioecological pressures. The documents confirm that stakeholders from all three regions are expecting to experience direct impacts from increased precipitation variability. These include changes in the overall amount, timing, and form of precipitation, as well as intensity of precipitation events. In all three regions, stakeholders from several sectors, including agriculture and forestry, natural resources and wildlife, and tourism and recreation voiced their concern regarding the potential negative impacts of related increases in hydrological variability. However, what aspects of these overall concerns (e.g., water quality or management challenges) emerge as a priority within the documents of each region reflects both the current and anticipated local-regional manifestation of precipitation variability and the interactions with the social, economic, and political contexts in which these changes are experienced.

As Fig. 1 outlines, in the Great Lakes region, information from the documents suggests that concerns about future changes in snowpack are elevated by worry that such changes will interact with modifications in ice coverage on the lakes during the winter months. Ultimately, while less ice coverage may increase winter precipitation, less of this precipitation is expected to fall as snow and more will melt before spring, changing groundwater replenishment and agricultural runoff patterns. As such, while concerns about depleting groundwater reservoirs, agricultural runoff, and "dead zones" may not be unique to the Great Lakes region, they are priority concerns in this region because of the specific way in which precipitation changes interact with the atmospheric, geographic, and socioecological characteristics of the region. Additionally, documents from the GLISA region expressed major concerns about the potential challenges changing precipitation patterns could present to the economically vital shipping industry of the Great Lakes, highlighting issues like shipping loads and dredging costs as regional priorities.

Alternatively, coastal development and population growth in the Carolinas over the past several decades coupled with the ecological and economic impacts of saltwater intrusion precipitated by drought and sea level rise has led to growing concerns about water management systems, public use and demand, and ecological degradation due to hypersaline conditions in rivers. The coastal tourism sector in this region is particularly concerned about these impacts. Extreme hydrologic events like drought, severe storms, and flooding are therefore a priority concern for water supply and utility managers in the Carolinas who are responsible for maintaining storm water infrastructure and ensuring water quality. In addition, the documents also point out other sectors of concern, such as business, tourism, and natural resources along the coastal area, where leaders and managers are charged with mitigating the impacts of saltwater intrusion.

Finally, the WWA region comprises most of the upper Colorado River basin and the headwaters for the entire Colorado River basin. Like the GLISA region, climate change is expected to lead to reduced snowpack and earlier snowmelt, which in turn could reduce overall flows of the Colorado River over the next several decades. Such flow reductions, when combined with increasing demands, could contribute to a supply and demand imbalance of 3.2 million acre-feet by midcentury (Bureau of Reclamation 2012). It is important to note that this is at the basin scale, and regional and local impacts could vary, but it does illuminate the growing recognition of the nonstationarity of climate. As a consequence, there is a focus in the documents on the development of policies, management systems, and mitigation procedures to address this potential supply-demand imbalance. 


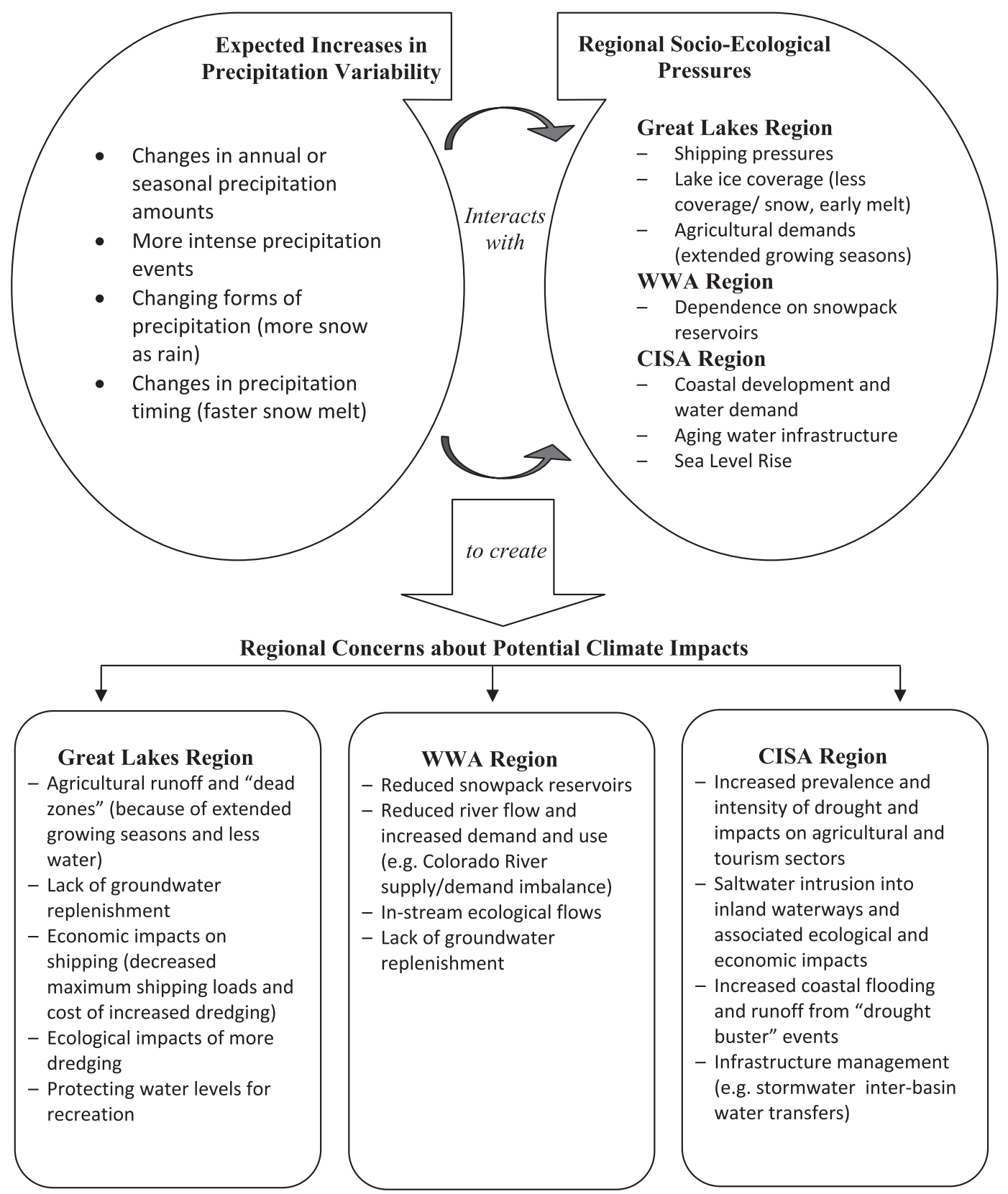

FIG. 1. Regional concerns about potential climate impacts.

\section{b. Stakeholder expressed needs}

Data from the documents suggest that stakeholder needs fall under three broad themes: first, improved information and decision support under uncertain socialpolitical and climatological conditions; second, governance issues, including coordination among data providers and stakeholders as well as enabling policies, legal frameworks, and planning processes to support mitigative or adaptive action; and third, better communication and education about climate change to diverse groups and interests. However, not all of these needs were explicitly articulated in the context of climate. Instead, stakeholders discussed many of these needs within broader concerns about sustainability, responsible resource management, and proactive planning. Each region reflected real differences in the specific needs expressed (see Table 2). As noted in 
TABLE 2. Stakeholder needs.

\begin{tabular}{|c|c|c|}
\hline CISA & GLISA & WWA \\
\hline \multicolumn{3}{|c|}{ Improved understanding of current processes influencing climate sensitivity } \\
\hline $\begin{array}{l}\text { Current resources and } \\
\text { withdrawals, environmental } \\
\text { needs and conditions }\end{array}$ & $\begin{array}{l}\text { Modeling of hydrological processes } \\
\text { that influence lake levels, water } \\
\text { availability, and quality } \\
\text { Monitoring and data collection }\end{array}$ & $\begin{array}{l}\text { Ecosystem health, groundwater } \\
\text { supplies, and the historic and } \\
\text { current connections between } \\
\text { hydrology and climate }\end{array}$ \\
\hline $\begin{array}{l}\text { Streamflow, water use and } \\
\text { withdrawals, groundwater, } \\
\text { coastal water levels and tides }\end{array}$ & $\begin{array}{l}\text { Groundwater, sediment transport, } \\
\text { local impacts, clear climate change } \\
\text { indicators } \\
\text { Integration of information }\end{array}$ & $\begin{array}{l}\text { Streamflow, snowpack, } \\
\text { sediment transport }\end{array}$ \\
\hline $\begin{array}{l}\text { Integration of existing monitoring } \\
\text { and measurement networks } \\
\text { (e.g., sea level rise, storm surge, } \\
\text { tides, water flows, and water quality) } \\
\text { throughout the coastal system }\end{array}$ & $\begin{array}{l}\text { Better integration of climate } \\
\text { change into existing models; } \\
\text { integration of cost-benefit } \\
\text { analyses into scenario planning } \\
\text { Legal frameworks }\end{array}$ & $\begin{array}{l}\text { Scenarios that incorporate user- } \\
\text { driven research and other } \\
\text { variables besides hydrology } \\
\text { and climate (e.g., water rights) }\end{array}$ \\
\hline $\begin{array}{l}\text { Comprehensive system of water } \\
\text { management (e.g., water allocation } \\
\text { and withdrawal permitting, assessment } \\
\text { of availability, efforts to enhance water } \\
\text { use efficiency and water quality) }\end{array}$ & $\begin{array}{l}\text { Integration of climate change } \\
\text { into regional agreements (e.g., } \\
\text { the Sustainable Water Resources } \\
\text { Agreement and accompanying Great } \\
\text { Lakes Compact, the Great Lakes } \\
\text { Water Quality Agreement) } \\
\text { Availability of resources and supportive policies }\end{array}$ & $\begin{array}{l}\text { Assessment of climate change } \\
\text { implications for existing water } \\
\text { rights system }\end{array}$ \\
\hline $\begin{array}{l}\text { Financial, staffing, and technical resources } \\
\text { to implement programs, research, } \\
\text { data collection, and information sharing }\end{array}$ & $\begin{array}{l}\text { Mainstreaming climate information } \\
\text { into everyday planning and management } \\
\text { decisions }\end{array}$ & $\begin{array}{l}\text { Adaptation policies, } \\
\text { comprehensive flexible plans } \\
\text { to facilitate response to future } \\
\text { uncertain conditions }\end{array}$ \\
\hline \multicolumn{3}{|c|}{ Collaboration } \\
\hline $\begin{array}{l}\text { Across and within management } \\
\text { levels and agencies }\end{array}$ & $\begin{array}{l}\text { Across jurisdictions, eight U.S. } \\
\text { states, and two Canadian provinces }\end{array}$ & $\begin{array}{l}\text { Between researchers and managers, } \\
\text { planners and managers; centralized } \\
\text { clearinghouse for climate } \\
\text { information and projects }\end{array}$ \\
\hline & Communications, education, and awareness & \\
\hline $\begin{array}{l}\text { Communication with decision makers } \\
\text { on the potential effects of climate } \\
\text { change on water resources, the tools } \\
\text { and strategies that could be used to } \\
\text { address those effects, and the value of } \\
\text { continued investment in water-related } \\
\text { projects and research to the } \\
\text { public and policy makers }\end{array}$ & $\begin{array}{l}\text { Better understanding of how to } \\
\text { communicate complicated information } \\
\text { to the general public and how } \\
\text { to integrate climate change communication } \\
\text { into public agencies' ongoing outreach } \\
\text { research }\end{array}$ & $\begin{array}{l}\text { Importance of drought management } \\
\text { and water conservation among } \\
\text { the public, make apparent the } \\
\text { connection between water supply and } \\
\text { climate change to the public at large }\end{array}$ \\
\hline
\end{tabular}

Fig. 1, these needs stem from the unique concerns that each region has and may help illuminate where the capacity to mitigate or prepare for climate impacts may be missing.

One set of needs revealed by the stakeholder documents relates to improving biophysical and climatological information and resource management decision support. First, documents from all three regions recommended efforts to improve "baseline" climate and hydrological data. Such data could be used to monitor local impacts, track long-term change, and inform water management and climate change adaptations such as water budgets and in-stream flow requirements. Document authors noted that such efforts can also improve overall understanding about the current processes that influence climate sensitivities and help in identifying climate change indicators and monitoring strategies for how impacts are unfolding locally in order to guide future decisions. In addition, improving monitoring, mapping, and modeling tools and identifying the thresholds where resource systems are at risk of disruption are needed to help inform risk assessments and water management decisions at the regional and community levels. 
Documents also articulated frustration that the lack of understanding about the potential impacts of climate change on regional water resources and priorities contributes to an uncertain decision-making environment with regards to water allocation, treatment, and infrastructure needs. Stakeholder documents discussed dissatisfaction with having inadequate understanding about which climate change information to use and about how to integrate that information into existing management and decision-making processes. Many of the WWA documents discussed climate change models as important to planning efforts, but they also noted uncertainty problems and issues of scale. The challenges of downscaling climate information (Fowler et al. 2007), and understanding how best to use it in practice (Barsugli et al. 2013), are well known in the literature and reinforced by our document study. For example, differences between downscaled projections for different parts of the Great Lakes region (e.g., midcentury seasonal precipitation projections for the area between Ontario and Wisconsin) demonstrate how climate change will vary from place to place. Similarly, documents noted that the complex topography of the WWA region contributes to the uncertainty of downscaled climate projections, especially at the local level. In the Carolinas, climate models do not agree on the direction or magnitude of precipitation change. Differences in model output make it difficult for end users to incorporate modeling into planning for future water usedemand scenarios.

GLISA documents expressed an interest in structured decision-support processes that would assist the regional stakeholders with making the most of having imperfect climate projections. Similarly, in the WWA region, water managers called for help in identifying or developing relevant tools for decision support, such as climate change-specific training programs. Further, assistance in evaluating climate projections to be used for water supply planning was discussed as important, given the range of (and uncertainty in) climate projections for the region. Several WWA documents noted the importance of improved scenario planning, the need for support and guidance regarding what information should be incorporated into local scenarios, and how uncertainty should be represented. Documents from the Carolinas did not indicate specific use of climate projections or scenario planning but did express the need for public communication, decision making, and planning-oriented tools like facilitation guides or easy-to-understand visual aids. Document authors expressed that these tools, as well as information about best management practices and local case studies, can be used to discuss climate models and assumptions in a nontechnical format with the public and policy makers. Finally, documents also cited guidance about and development of methods to integrate various types and sources of information (including socioeconomic data, water availability and use information, cost-benefit analyses, and regulatory and legal requirements) into climate-related planning processes as a key need across the regions. For example, CISA documents generally discussed how increasing demands for variable and uncertain water supplies may have substantial economic and financial ramifications and may contribute to future competition and conflict over water resources.

A second set of needs focused on the policies, institutions, and other factors that can either enable or constrain the ability of regional stakeholders to address and adapt to climate impacts on water resources. The legal frameworks that govern water management vary significantly across the study regions, thereby shaping how stakeholders articulated the potential opportunities and needs associated with water resources adaptations. For example, climate change may complicate agreements negotiated between the Great Lakes states and Canadian provinces for managing their water supply and protecting degraded ecosystems. In the Carolinas, the lack of a comprehensive water allocation permitting system and set of water use standards contributes to conflicting water-related practices and programs as well as limited opportunities and incentives to adopt new management strategies or tools. In the WWA region, water is allocated through a complex system of rights dating back to the 1800 s. Documents reflected the significance of regional water law in their emphasis on the need to understand the impact of changes in the amount and timing of precipitation for the allocation of water. Furthermore, the availability of water impacts legally mandated protection of endangered species, complicating the task of water allocation decision making under uncertain conditions.

Needs for supportive policies, availability of resources, and enhanced collaboration were additional themes that emerged across all three regions. However, regional documents demonstrated nuances in how stakeholders articulated specific needs. Great Lakes regional documents consistently expressed a desire for assistance with mainstreaming, that is incorporating climate information in current decision and policy making rather than developing stand-alone climate policies (Bierbaum et al. 2013; Kok and de Coninck 2007). They also expressed an interest in developing cost-benefit analyses, especially ones targeted to potential adaptation decisions. In the Carolinas, documents indicated that a lack of resources constrains not only the ability of water managers to explore management 
options under various future climate and use-demand scenarios but also the implementation of any proposed measures to mitigate or adapt to climate change. Documents from both the Carolinas and WWA regions expressed a need for comprehensive and flexible plans to facilitate responses to future variable and uncertain conditions and contingencies.

Interjurisdictional collaboration on monitoring and managing climate change impacts is a high concern in the Great Lakes region, where resources are shared across an international border, eight U.S. states, and two Canadian provinces. In the Carolinas, documents stressed the need to identify state and local agency roles and responsibilities, coordinate actions across agencies and organizations, and support regional or watershed approaches to water management in order to address the lack of integration across water programs and issues associated with uncoordinated data collection. WWA documents reflected a similar need to coordinate and collaborate among all of the various activities underway in that region. The sharing of data, coordination between scientists working in the region, and perhaps even a "clearinghouse" activity that would serve as a centralized source of information and analysis from various entities were identified as solutions that would help in this area.

A third set of needs common throughout the three regions related to the communication of climate change information. Recommendations focused on providing education about climate change impacts and improving understanding of the processes and methods through which climate information can be most effectively delivered to a variety of audiences. For example, in the Great Lakes region, documents pointed out a need to reframe the public's understanding of the role of science, as stakeholders felt that science is sometimes perceived solely as a source of answers, rather than as an ongoing process; also, impacts need to be framed into factors or indicators that are tangible and relevant for the public. In contrast with other needs described above, communication and education activities are explicitly connected to climate and strive to increase awareness of climate change among the public and policy makers. Implicit in the documents is the idea that improved awareness of the connections between climate and water resources will contribute to greater support for climate adaptations and allocation of resources to support water management.

\section{Summary: Diverse contexts, common needs}

Decision makers at all levels have already been strongly engaged in discovering and expressing their climate-related needs in a wide variety of venues in the three regions studied, although not all regions had the same level of engagement with climate change as a specific topic. The nature of the climate discussion is different in each region, reflecting the different political, social, environmental, and experiential processes at work in each region. For example, in the WWA and Great Lakes regions, the impacts of both climate variability and climate change on water resources were vigorously discussed in the analyzed documents, whereas in the Carolinas, discussions involving climate mainly focused on extremes, seasonal variability, and coastal flooding. In all three regions, however, crisis events such as droughts, saltwater intrusion, or dropping lake levels seemed to bring greater attention to and engagement with the role of climate in water management.

Despite the different climate signals and conversations evident in the study regions, we found that the climaterelated needs expressed by stakeholders fit into three overarching categories of needs: 1) data and information; 2) coordination, governance, and legal frameworks; and 3) communication and education. We highlight here some of the findings within these themes that are robust across regions and have strong implications for the provision of climate services. The final sections discuss some of the questions about the provision of climate services raised by diverse regional contexts.

\section{a. Common needs across regions}

\section{1) Better data ABOUT THE HeRE AND NOW}

Concerning data and information, while climate change will have significant impacts on water resources, scenarios of future change are only one type of information that stakeholders lack for making improved decisions. To better manage water resources, stakeholders mentioned the need for better data on the existing water system, including additional hydrologic, groundwater, and sediment monitoring, as well as more accurate, real-time, accessible withdrawal and consumptive use data. Such data do not rely on projecting the future, but rather imply a need to better instrument and monitor our existing supplies and demands. Unfortunately, support for baseline monitoring is eroding in some regions rather than increasing (Dilling and Berggren 2014; USGS 2013). In such an environment, all regions highlighted the need for different entities to coordinate and collaborate in collecting data, disseminating research results, and sharing the costs and responsibilities for monitoring efforts. Furthermore, climate concerns were frequently expressed in terms of how climate interacts with (or might interact in the future, under climate change) other stressors, processes, 
and conditions to produce adverse impacts (e.g., population growth, development, and land use change). Accordingly, efforts to collect and interpret data on the hydrological impacts of climate variability and change need to include additional factors that take into consideration the socioecological context in which such impacts are experienced and responded to such as land use regulations and planning, water governance measures, species protection laws, energy generation, public revenue models, and the like.

\section{2) RECEPTIVE LEGAL FRAMEWORKS AND SUPPORTIVE GOVERNANCE}

As has been previously discussed, both the knowledge generation aspect of the science-policy-practice interface and the decision-making context itself can serve as barriers to the effective use of information and to building adaptive capacity (Dilling and Lemos 2011; Eakin et al. 2011; Weichselgartner and Kasperson 2010). Stakeholders in the study regions clearly acknowledged that gaps in the knowledge and data generation enterprise are important and that opportunities for better coordination of the substantial resources may already be available. However, the structure of existing governance and legal frameworks that influence water use, treatment, and allocation is also a major barrier. These structures can constrain stakeholders' ability to integrate existing knowledge of water and climate variability, not to mention climate change projections, into better decisions. In some cases, lack of financing for alternatives, support for mainstreaming climate into existing decision processes, and resources for adaptation plans contributed to the inability to improve management decisions. Decisions about legal frameworks, mainstreaming climate, and new methods for allocating water take place in venues often distant from the local decision makers and resource managers who use and need climate information to make a variety of operational and planning decisions (Kiparsky et al. 2012; Pahl-Wostl 2009).

\section{3) ENHANCED PUBLIC COMMUNICATION}

The need for better sharing of information among regional information providers and boundary organizations was another robust finding, especially in areas where stakeholders had been discussing climate impacts on water resources for over a decade. The challenge of communicating to the public the implications of climate for water resources and planning in both the near and far term was also a consistent theme across regions [echoing findings on drought communication more broadly, e.g., Steinemann (2014)].

\section{b. Improving climate information provision in diverse contexts}

Through this project, the authors sought to use existing documents (e.g., previous assessments and similar efforts) to develop a baseline understanding of decision makers' climate concerns and needs within three U.S. regions. Our experience and combined databases suggest that reviewing previously expressed needs, whether through document analysis or alternate methods, is a good first step for understanding the climate-related challenges and capacities of stakeholders in a region. This project also raises important questions regarding how to most effectively and efficiently build adaptive capacity for climate change and variability, especially at the knowledge-practice interface and given the range of concerns and needs identified by decision makers. Here we highlight some of the challenges associated with closing the usability gap (Lemos et al. 2012) and suggest some possible opportunities to advance our thinking about managing the science-policy-practice interface.

\section{1) ACKNOWLEDGE CONSTRAINTS BEYOND THE DATA AND INFORMATION ARENA}

A comprehensive understanding of the full suite of constraints and opportunities that exist within a given decision-making context is important for information providers operating in the complex and ever-changing environment that is climate adaptation decision making. Stakeholders expressed a wide variety of needs for climate-related information across a wide range of sectors. It is clear that stakeholders also are looking for increasing interactions with information providers so that the needs can be met with the most timely and relevant data.

However, judging by the range of climate-related needs expressed by stakeholders that went beyond needs typically addressed by information providers, the capacity to generate information and the ability to produce appropriate governance solutions may in itself not be sufficient to lead to effective decision support. From the consistent yet wide variety of needs expressed by decision makers in these documents, it is fair to say that the current ability to respond to climate variability and change is still constrained in multiple ways (e.g., in the way that existing regulations function, or limitations on management options). Furthermore, climate change may compound existing constraints and require engagement with new challenges at different scales, for example, stressors such as population growth, land use change, and urbanization that are expected to interact with climate to affect water resources (Berkhout 2012). 


\section{2) LEVERAGE AND COORDINATE EXISTING NETWORKS AND CAPACITIES}

The fact that stakeholders enter a relationship with information providers through particular trusted connections and that those providers may only be able to address a portion of the needs that stakeholders have in meeting climate challenges may result in the creation of different and sometimes parallel schemes to address the gap between needs and ability to provide information [e.g., creation of networks, boundary organizations, and objects; for examples, see Dow et al. (2013) and Lemos et al. (2014)]. One interesting question that emerges from this research is, how do decision makers' abilities to make effective climate-related decisions depend on the collaboration and coordination between information production and communication and organizations that use information to improve adaptive capacity? This analysis indicates that these areas are not independent, and in some cases, are directly interdependent.

As a first step, all regions highlighted the need to coordinate and collaborate in collecting data, sharing research results, and integrating strategies and programs for water-related decision making. This finding suggests that while data and information are clearly lacking in some areas, there are some opportunities for better coordination of the substantial resources that are already available in the regions. Moreover, this suggests that any one organization providing a piece of the decisionsupport puzzle must be more aware of who the other players are and what they might provide. Many organizations operating in this space have a limited mandate. For example, while one organization may provide data on streamflow, it probably has neither the mandate nor the resources to install additional snowpack monitoring stations. In an era when governmental organizations at all levels are being challenged to operate efficiently and eliminate redundancies, a necessary component of effective decision support means creating a way to assess assets, share information, and connect actors to the resources that may already exist or to the most logical home for new resources that might be needed. Unfortunately, individual organizations often do not undertake such a clearinghouse role since they do not have the mandate or resources to do so, although the National Integrated Drought Information System (NIDIS) now serves a key integrating function for disseminating drought information and galvanizing warning systems.

\section{3) EXPAND THE INTERFACE}

To fully support the development of adaptive capacity, there is also the need for mechanisms to facilitate the connection of decision makers to other types of organizations and networks and for them to be able to connect among themselves (Bidwell et al. 2013). From a science-policy perspective, this may point to the need to focus energy on the interstices, the connections between nodes, and ways of facilitating rather than focusing only on the organizations themselves. For example, some organizations are better positioned to cope with and adapt to climate change than others because of institutional factors such as the types of guidance documents in use and whether they allow for flexible decision making (Farley et al. 2011; Roncoli et al. 2012). What may be needed are processes to build connections so that multiple aspects of stakeholders' needs can be efficiently and effectively addressed. Vogel et al. (2007, p. 351) suggest that the science-practice interface should be viewed as "spider webs of connectivity and exchange" or "a complex terrain that is best described as a multilevel system of governance and knowledge production among a range of actors engaged in understanding and managing environment-society interactions" (see also Cash and Moser 2000; Cash et al. 2006; Weichselgartner and Kasperson 2010). A smarter, more adaptive, and better-connected network with a more diverse set of organizational actors may produce more collective capacity to adapt than single organizations acting alone, or worse, single organizations all scrambling to compete for the same parcel of knowledge-action real estate.

\section{Conclusions}

Our analysis of documents from three regions of the United States suggests that the way stakeholders describe their decision contexts and express their needs related to climate may indicate that adaptive capacity for climate in these regions is limited in some important ways. The capacity of organizations in our regions to effectively build and take advantage of decision-support opportunities is often influenced by factors beyond the supply of information, although information supply, access, and usability can be limited as well.

These findings further suggest that it is important to understand the nature of the system into which any one organization is providing information, as some issues are common across regions and other issues and needs are regionally specific. Questions like those raised in this research regarding the variables that shape climate decision-support needs, the pathways through which climate information is disseminated and utilized, and the contextual factors that mediate the use of such information are of increasing significance for multilateral efforts to build adaptive capacity. To further adaptive 
capacity, the connections between organizations and their functional roles must be more deliberately illuminated and supported, while maintaining the fluidity and agility needed throughout the knowledge-action network as a whole. These efforts must also take into consideration that the responsibility for increasing the usability of science needs to be shared by researchers, practitioners, and other stakeholders and forged through their continuous interaction-which also can bring out the tensions among different kinds of information and the ability of different actors to use them (van Kerkhoff and Lebel 2006). In this way, as needs emerge, they can be more appropriately directed and gaps in the overall and regional capacity to support decision making can be identified.

Acknowledgments. The authors gratefully acknowledge support from the National Oceanic and Atmospheric Administration Climate Program Office through the Carolinas Integrated Sciences and Assessment RISA Grant NA060AR4310007 (K.D., K.L., and B.H.), the Western Water Assessment RISA at CIRES Grant NA10OAR4310214 (L.D. and J.B.), and the Great Lakes Integrated Sciences and Assessment RISA Grant NA10OAR4310213 (M.C.L. and S.K.).

\section{REFERENCES}

Adger, W. N., and Coauthors, 2007: Assessment of adaptation practices, options, constraints and capacity. Climate Change 2007: Impacts, Adaptation and Vulnerability, M. L. Parry et al., Eds., Cambridge University Press, 717-743.

Archie, K. M., L. Dilling, J. B. Milford, and F. C. Pampel, 2014: Unpacking the "information barrier": Comparing perspectives on information as a barrier to climate change adaptation in the interior mountain West. J. Environ. Manage., 133, 397410, doi:10.1016/j.jenvman.2013.12.015.

Barsugli, J. J., and Coauthors, 2013: The practitioner's dilemma: How to assess the credibility of downscaled climate projections. Eos, Trans. Amer. Geophys. Union, 94, 424-425, doi:10.1002/ 2013EO460005.

Berkhout, F., 2012: Adaptation to climate change by organizations. Wiley Interdiscip. Rev.: Climate Change, 3, 91-106, doi:10.1002/ wcc.154.

Bidwell, D., T. Dietz, and D. Scavia, 2013: Fostering knowledge networks for climate adaptation. Nat. Climate Change, 3, 610611, doi:10.1038/nclimate1931.

Bierbaum, R., and Coauthors, 2013: A comprehensive review of climate adaptation in the United States: More than before, but less than needed. Mitigation Adapt. Strategies Global Change, 18, 361-406, doi:10.1007/s11027-012-9423-1.

Bureau of Reclamation, cited 2012: Colorado River basin water supply and demand study: Executive summary. Bureau of Reclamation, 28 pp. [Available online at www.usbr.gov/lc/ region/programs/crbstudy/finalreport/Executive\%20Summary/ CRBS_Executive_Summary_FINAL.pdf.]

Cash, D. W., 2001: "In order to aid in diffusing useful and practical information": Agricultural extension and boundary organizations. Sci. Technol. Human Values, 26, 431-453, doi:10.1177/016224390102600403.

_ _ and S. C. Moser, 2000: Linking global and local scales: Designing dynamic assessment and management processes. Global Environ. Change, 10, 109-120, doi:10.1016/S0959-3780(00)00017-0.

—, W. Clark, F. Alcock, N. M. Dickson, N. Eckley, D. H. Guston, J. Jager, and R. B. Mitchell, 2003: Knowledge systems for sustainable development. Proc. Natl. Acad. Sci. USA, 100, 8086-8091, doi:10.1073/pnas.1231332100.

— approach to linking science and decision making. Sci. Technol. Human Values, 31, 465-495, doi:10.1177/0162243906287547.

Dilling, L., and J. Berggren, 2014: What do stakeholders need to manage for climate change and variability? A document-based analysis from three mountain states in the western USA. Reg. Environ. Change, doi:10.1007/s10113-014-0668-y, in press.

— nities and constraints for climate knowledge use and their implications for science policy. Global Environ. Change, 21, 680-689, doi:10.1016/j.gloenvcha.2010.11.006.

_ , and E. Failey, 2013: Managing carbon in a multiple use world: The implications of land-use decision context for carbon management. Global Environ. Change, 23, 291-300, doi:10.1016/ j.gloenvcha.2012.10.012.

Dow, K., B. K. Haywood, N. P. Kettle, and K. Lackstrom, 2013: The role of ad hoc networks in supporting climate change adaptation: A case study from the southeastern United States. Reg. Environ. Change, 13, 1235-1244, doi:10.1007/s10113-013-0440-8.

Eakin, H., S. Eriksen, P.-O. Eikeland, and C. Øyen, 2011: Public sector reform and governance for adaptation: Implications of new public management for adaptive capacity in Mexico and Norway. Environ. Manage., 47, 338-351, doi:10.1007/ s00267-010-9605-0.

Farley, K. A., C. Tague, and G. E. Grant, 2011: Vulnerability of water supply from the Oregon Cascades to changing climate: Linking science to users and policy. Global Environ. Change, 21, 110-122, doi:10.1016/j.gloenvcha.2010.09.011.

Feldman, D. L., and H. M. Ingram, 2009: Making science useful to decision makers: Climate forecasts, water management, and knowledge networks. Wea. Climate Soc., 1, 9-21, doi:10.1175/ 2009WCAS1007.1.

Fowler, H. J., S. Blenkinsop, and C. Tebaldi, 2007: Linking climate change modelling to impacts studies: Recent advances in downscaling techniques for hydrological modelling. Int. J. Climatol., 27, 1547-1578, doi:10.1002/joc.1556.

Frank, K., I.-C. Chen, Y. Lee, S. Kalafatis, T. Chen, Y.-J. Lo, and M. C. Lemos, 2012: Network location and policy-oriented behavior: An analysis of two-mode networks of coauthored documents concerning climate change in the Great Lakes region. Policy Stud. J., 40, 492-515, doi:10.1111/j.1541-0072.2012.00462.x.

Glaas, E., A. Jonsson, M. Hjerpe, and Y. Andersson-Sköld, 2010: Managing climate change vulnerabilities: Formal institutions and knowledge use as determinants of adaptive capacity at the local level in Sweden. Local Environ., 15, 525-539, doi:10.1080/ 13549839.2010.487525.

Gregory, R., L. Failing, M. Harstone, G. Long, T. McDaniels, and D. Ohlson, 2012: Structured Decision Making: A Practical Guide to Environmental Management Choices. Wiley, $312 \mathrm{pp}$.

Haywood, B. K., A. Brennan, K. Dow, N. P. Kettle, and K. Lackstrom, 2014: Negotiating a mainstreaming spectrum: Climate change response and communication in the Carolinas. J. Environ. Policy Plann., 16, 75-94, doi:10.1080/1523908X.2013.817948. 
Hegger, D., M. Lamers, A. Van Zeijl-Rozema, and C. Dieperink, 2012: Conceptualising joint knowledge production in regional climate change adaptation projects: Success conditions and levers for action. Environ. Sci. Policy, 18, 52-65, doi:10.1016/ j.envsci.2012.01.002.

Jacobs, K., G. Garfin, and M. Lenart, 2005: More than just talk: Connecting science and decisionmaking. Environment, 47, 6 21, doi:10.3200/ENVT.47.9.6-21.

_ - and Coauthors, 2010: Linking knowledge with action in the pursuit of sustainable water-resources management. Linking Knowledge with Action for Sustainable Development: 8th Annual Sackler Colloquia, Washington, DC, National Academy of Sciences, 6 pp., doi:10.1073/pnas.0813125107.

Kasperson, R. E., 2006: Rerouting the stakeholder express. Global Environ. Change, 16, 320-322, doi:10.1016/j.gloenvcha.2006.08.002.

Kiparsky, M., A. Milman, and S. Vicuña, 2012: Climate and water: Knowledge of impacts to action on adaptation. Annu. Rev. Environ. Resour., 37, 163-194, doi:10.1146/ annurev-environ-050311-093931.

Kirchhoff, C. J., M. C. Lemos, and S. Dessai, 2013: Actionable knowledge for environmental decision making: Broadening the usability of climate science. Annu. Rev. Environ. Resour., 38, 393-414, doi:10.1146/annurev-environ-022112-112828.

Klein, R. J. T., G. F. Midgley, B. Preston, M. Alam, F. G. H. Berkhout, K. Dow, and M. R. Shaw, 2014: Adaptation opportunities, constraints, and limits. Climate Change 2014: Impacts, Adaptation, and Vulnerability. C. B. Field et al., Eds., Cambridge University Press. [Available online at http://www. ipcc.ch/report/ar5/wg2/.]

Kok, M., and H. de Coninck, 2007: Widening the scope of policies to address climate change. Environ. Sci. Policy, 10, 587-599, doi:10.1016/j.envsci.2007.07.003.

Lach, D., P. List, B. Steel, and B. Shindler, 2003: Advocacy and credibility of ecological scientists in resource decisionmaking: A regional study. Bioscience, 53,170-178, doi:10.1641/ 0006-3568(2003)053[0170:AACOES]2.0.CO;2.

Lackstrom, K., N. P. Kettle, B. Haywood, and K. Dow, 2014: Climatesensitive decisions and time frames: A cross-sectoral analysis of information pathways in the Carolinas. Wea. Climate Soc., 6, 238-252, doi:10.1175/WCAS-D-13-00030.1.

Lemos, M. C., C. J. Kirchhoff, and V. Ramprasad, 2012: Narrowing the climate information usability gap. Nat. Climate Change, 2, 789-794, doi:10.1038/nclimate1614.

,-- _ S. E. Kalafatis, D. Scavia, and R. B. Rood, 2014: Moving climate information off the shelf: Boundary chains and the role of RISAs as adaptive organizations. Wea. Climate Soc., 6 , 273-285, doi:10.1175/WCAS-D-13-00044.1.

Lowrey, J. L., A. J. Ray, and R. S. Webb, 2009: Factors influencing the use of climate information by Colorado municipal water managers. Climate Res., 40,103-119, doi:10.3354/cr00827.

McNie, E., 2007: Reconciling the supply of scientific information with user demands: An analysis of the problem and review of the literature. Environ. Sci. Policy, 10, 17-38, doi:10.1016/ j.envsci.2006.10.004.

Moser, S. C., and J. A. Ekstrom, 2010: A framework to diagnose barriers to climate change adaptation. Proc. Natl. Acad. Sci. USA, 107, 22 026-22 031, doi:10.1073/pnas.1007887107.

Moss, R. H., and Coauthors, 2013: Hell and high water: Practicerelevant adaptation science. Science, 342, 696-698, doi:10.1126/ science.1239569.

Naess, L. O., G. Bang, S. Eriksen, and J. Vevatne, 2005: Institutional adaptation to climate change: Flood responses at the municipal level in Norway. Global Environ. Change, 15, 125-138, doi:10.1016/j.gloenvcha.2004.10.003.

National Research Council, 2009: Informing Decisions in a Changing Climate. Panel on Strategies and Methods for ClimateRelated Decision Support. National Academies Press, 200 pp.

Pahl-Wostl, C., 2009: A conceptual framework for analysing adaptive capacity and multi-level learning processes in resource governance regimes. Global Environ. Change, 19, 354 365, doi:10.1016/j.gloenvcha.2009.06.001.

Pielke, R. A., Jr., 2007: The Honest Broker: Making Sense of Science in Policy and Politics. Cambridge University Press, $188 \mathrm{pp}$.

Pulwarty, R. S., C. Simpson, and C. R. Nierenberg, 2009: The Regional Integrated Sciences and Assessments (RISA) Program: Crafting effective assessments for the long haul. Integrated Regional Assessment of Global Climate Change, C. G. Knight and J. Jäger, Eds., Cambridge University Press, 1-28.

Ray, A., G. Garfin, M. Wilder, M. Vasquez-Leon, M. Lenart, and A. C. Comrie, 2007: Applications of monsoon research: Opportunities to inform decision making and reduce regional vulnerability. J. Climate, 20, 1608-1627, doi:10.1175/ JCLI4098.1.

Rayner, S., D. Lach, and H. Ingram, 2005: Weather forecasts are for wimps: Why water resource managers do not use climate forecasts. Climatic Change, 69, 197-227, doi:10.1007/ s10584-005-3148-z.

Roncoli, C., N. Breuer, D. Zierden, C. Fraisse, K. Broad, and G. Hoogenboom, 2012: The art of the science: Climate forecasts for wildfire management in the southeastern United States. Climatic Change, 113,1113-1121, doi:10.1007/s10584-012-0526-1.

Sarewitz, D., and R. Pielke Jr., 2007: The neglected heart of science policy: Reconciling supply of and demand for science. Environ. Sci. Policy, 10, 5-16, doi:10.1016/j.envsci.2006.10.001.

Smit, B., and J. Wandel, 2006: Adaptation, adaptive capacity and vulnerability. Global Environ. Change, 16, 282-292, doi:10.1016/ j.gloenvcha.2006.03.008

Steinemann, A., 2014: Drought information for improving preparedness in the western states. Bull. Amer. Meteor. Soc., 95, 843-847, doi:10.1175/BAMS-D-13-00067.1.

Tribbia, J., and S. C. Moser, 2008: More than information: What coastal managers need to plan for climate change. Environ. Sci. Policy, 11, 315-328, doi:10.1016/j.envsci.2008.01.003.

USGS, cited 2013: USGS threatened and endangered stations. [Available online at http://streamstatsags.cr.usgs.gov/ ThreatenedGages/ThreatenedGages.html.]

van Kerkhoff, L., and L. Lebel, 2006: Linking knowledge and action for sustainable development. Annu. Rev. Energy Environ., 31, 445-477, doi:10.1146/annurev.energy.31.102405.170850.

Vogel, C., S. C. Moser, R. E. Kasperson, and G. Dabelko, 2007: Linking vulnerability, adaptation, and resilience science to practice: Pathways, players, and partnerships. Global Environ. Change, 17, 349-364, doi:10.1016/j.gloenvcha.2007.05.002.

Weichselgartner, J., and R. Kasperson, 2010: Barriers in the sciencepolicy-practice interface: Toward a knowledge-action-system in global environmental change research. Global Environ. Change, 20, 266-277, doi:10.1016/j.gloenvcha.2009.11.006.

Yin, R. K., 2003: Case Study Research: Design and Methods. 3rd ed. Sage Publications, $200 \mathrm{pp}$.

Yohe, G., and R. Tol, 2002: Indicators for social and economic coping capacity-Moving toward a working definition of adaptive capacity. Global Environ Change, 12, 25-40, doi:10.1016/S0959-3780(01)00026-7. 